\title{
Expected Qualities of a Lecturer: Perceptions of Medical Students in a Remote Setting
}

\author{
Thilini C Agampodi ${ }^{1}$, Eranga S Thalagala ${ }^{1}$, Sahan J Perera ${ }^{1}$, Shashika Chandrarathna ${ }^{1}$, Suneth \\ Agampodi $^{1}$, Sisira Siribaddana ${ }^{1}$
}

\begin{abstract}
Studies on medical student perceptions of their lecturers, in a resource poor setting is scarce. Lack of basic infrastructure hampers learning. Quality lecturers can compensate this handicap to some extent. In 2009, as a new medical school located in rural Sri Lanka $220 \mathrm{~km}$ away from Colombo, the Faculty of Medicine and Allied Sciences at Rajarata University had scarce human resources and lacked sufficient lecture halls, labs, and clinical space. In order to understand qualities students sought in a lecturer, 55 medical students were given a single, self-administered open-ended question, and responses were subjected to direct thematic analysis. Themes of "Lecturer Qualities," "Lecture Preparation Procedure," and "Lecture Delivery Procedure" were identified, and then further divided into sub-themes, the most common of which being "Speaking Style," "Content Design," and "Content Organization." While the findings in this study closely mirrored those of similar studies, identified qualities were underpinned by implicit meaning that accurately reflects the emotional stressors among students coping with limited educational resources. Students emphasized the importance of clear communication due to language barriers and a strong desire for lecturer loyalty to their faculty and country. The examination of these real-life perceptions will not only help us better identify how to improve medical education in this medical faculty and may be useful to similar resource poor rural medical colleges around the world.
\end{abstract}

Key words: Medical students' expectations; Lecturer qualities; Qualitative method; Resource poor new setting; Sri Lanka

\section{Introduction}

According to Henzi, "Students are the group affected the most by their education, but oftentimes they feel they have the least amount of input for change" (Henzi et al., 2005). Studies that look at student's perceptions of their education attempt to combat the notion in this statement by taking into account student wants and needs in order to improve the educational system are always welcome.

\footnotetext{
${ }^{1}$ Department of Community Medicine, Faculty of Medicine and Allied Sciences, Rajarata University of Sri Lanka

Corresponding author:

Prof. Sisira Siribaddana,

Department of Medicine

(Teaching Hospital Anuradhapura),

Faculty of Medicine and Allied Sciences,

Saliyapura, Sri Lanka

E-mail:nipuna@stmail.lk
}

In a study among medical and dental students, Jahangiri and Mucciolo (2008) report that the top priority in terms of learning were "content design," "content organization," "content development," "expertise," and "speaking style".

However, in a resource poor environment, such as the one found at the Faculty of Medicine and Allied Sciences (FMAS), Rajarata University of Sri Lanka (RUSL), Henzi's original statement is amplified as medical students face additional challenges to receiving a quality education. By definition, a "limited resource setting" is one in which there is difficulty meeting the basic needs of an environment, whatever this may be. Situated two hundred and forty kilometres away from the capital city of Colombo, the rural location of FMAS, RUSL falls within this definition. Although the Faculty of Medicine is only four years old, its physical infrastructure is dilapidated and it lacks sufficient audio-visual 
equipment, labs, lecture halls, and clinical space. Except for a few members of the academic staff working on contract basis as consultants, the majority of lecturers were new and have less than three years of teaching experience.

The curriculum is largely lecture-based with some laboratory requirements in the primary years and then shifts to a clinical focus in the latter years. Due to the emphasis on lectures and the university's limited alternative educational resources, having quality lecturers that the students can connect with is of the utmost importance.

Other studies have also found that the expectations of students vary according to the learning environment and resources available to them (Redding \& Walberg, 2012; Maheux et al., 2000; Nahar, 2010). Redding discusses the student-teacher relationship, and the positive effects of teacher enthusiasm on student motivation and performance in a rural setting (Redding, 2012). Maheux's further articulates the importance of humanism in the learning environment in both traditional and innovative medical schools (Maheux, 2000).

This study strives to take a unique approach to the classic question of 'medical students' perceptions on expected qualities of a university lecturer" by focusing on how these perceptions change in the context of a limited resource setting.

\section{Methods}

\section{Study design}

Selected medical undergraduates were given an open-ended question, to which they were asked to write a response. The responses were then subjected to qualitative analysis in order to determine the most common qualities of a good lecturer identified by students. Previous studies have found that qualitative analysis can provide valuable information in planning a new curriculum to strengthen teacher training in medical education (Khan \& Fareed, 2003; Ho \& Tani, 2007). We chose this method with hopes that students would not be limited to traditional themes of a good lecturer, and to elicit honest responses that could be used to produce necessary behavioural change among lecturers in the future.

The participants were in the third year of the six-year undergraduate medical program, and were the first entering class at FMAS, RUSL.
These students have had the most exposure to lecturers at the Faculty of Medicine, and had spent the most time studying medicine in a rural, low-resource setting. Therefore, the population of participants was limited to this class, with the hope that they could give the most accurate depiction of an effective lecturer.

The method of data collection was chosen for several reasons. The investigators were academic staff and participants were their students. Thus, there was a concern that faceto-face interaction, such as personal interviews or focus groups, would deter students from giving honest opinions. Furthermore, the selected students were preparing for the third MBBS part two examination, and time-consuming qualitative data collection would deter the majority of students from participating in this voluntary study. For these reasons, a single selfadministered open-ended question was given.

The open-ended question was chosen based on Pai, who explored children's expectations of their parents (Pai, 1993). The English version is given below:

"If you are able to order a lecturer from a place where they can accomplish all your wishes, write a description of the lecturer that you wish to have, to teach you during this course"

In Pai's study, this question was shown to reflect honest expectations and perceptions of the participants. The initial phrase "ordering a lecturer from a place that accomplish your wishes" was thought to encourage students to think broadly rather than just listing the good and bad qualities of lecturers. This question was originally constructed in Sinhalese and later translated to English. Both versions were given to the students and they were instructed to answer in their preferred language.

\section{Procedure}

There were 164 registered students in this batch, and on average, attendance per lecture in that year was 75. Attending a lecture was assumed to be a proxy measure of a lecturebased learning technique; hence, their answers supposedly insightful. When choosing when to conduct the study, we took into consideration that immediately after a lecture, student comments might be biased by their recent lecture experience. Therefore, we selected a time when the first lecture of the day was cancelled in September 2009. All the students attending were asked to participate. 
After explaining the objectives and emphasizing the voluntariness of the study, we invited the students at a lecture theatre to participate. A demonstrator (recent medical school graduate) was trained to inform students about the purpose of the study and deliver the question script. Once the question was answered anonymously, students themselves collected the answer papers. At this stage, the students were given the opportunity to either hand over what they documented or keep it. No additional information was collected from students. Ethical approval was obtained from the Ethics Review Committee, FMAS, RUSL.

\section{Analysis}

Student perceptions on qualities of lecturer are well documented and framework for analysis is already available in the literature (Henzi et al., 2005). We commenced with inductive data analysis from the raw data using direct qualitative content analysis (Zhang \& Wildemuth, 2009). Subsequently, identified themes were organized into framework described in the literature (Berg, 2001).

A word, phrase, sentence or a paragraph which describes a particular quality of a lecturer or lecturing style was considered as a "theme" (Boyatzis, 1998). A coding manual was developed to maintain consistency and ambiguous responses were discussed among all five investigators and discrepancies reconciled. The manual contained themes, sub-themes, and rules for inclusion. These rules were decided and agreed upon by five investigators. The different themes in each answer sheet were identified, separated, cut and collated manually. Five investigators (TA, $\mathrm{ET}, \mathrm{SP}, \mathrm{SC}$, and SA) went through the collated lots of themes with agreement by consensus. New themes that copped up later were added to the manual. All investigators used the constant comparative method (Glaser \& Strauss, 1967) to develop sub-themes in separated lots and to refine the themes. All five investigators collectively analysed and categorized the responses together simultaneously to improve the coding reliability. Responses that were difficult to understand were discarded. At the end of this process, we renamed and re-categorized themes and subthemes according to the available framework in the medical educational literature (Table 1). Conscious effort was taken during the process of ascribing to prevent masking of real life expressions contained in raw data. The data analysis was rechecked independently by the senior author (SS). Selected quotations from raw data have been used to highlight the participants' view (Horsfall et al., 2001).

\section{Results}

Of the 68 medical students who were present for the lecture on the day of the study, 55 (81\%) participated. There were 419 individual responses and 20 sub-themes. Table one presents the sub-themes, their definitions and the responses. Three overarching themes were inductively formed by amalgamating the sub-themes. These themes were defined as "personal qualities", "lecture preparation" and "lecture delivery".

The sub-theme "speaking style" which was under "lecture delivery" had the highest number of responses. Other popular subthemes included "content design" and "content organization," which fell under the theme of "lecture preparation".

\section{Personal qualities of lecturers}

\section{Approachability}

The students appreciated lecturers who were friendly, approachable and kind.

"When the lecturer shows kindness we develop a desire to learn and the process is tireless."

According to them, lecturers should be available to consult with individually outside of the designated lecture time.

\section{Dedication}

Students expected lecturers to be dedicated.

"A lecturer should be a person who utilizes the time for the benefit of students."

"A lecturers' responsibility should not end merely by wiping his/her hands off after the lecture."

\section{Empathy}

Students expected a lecturer to understand the feelings as well as different social backgrounds of students.

\footnotetext{
"A lecturer should be kind hearted and able to think like us, imagining that he/she was in the same age and situation."

"The lecturer should understand students' with varying abilities and knowledge, so attention could be paid accordingly."
} 


\section{Expertise}

Students desired knowledgeable, talented, and skilled lecturers who could teach complex facts in an easily comprehensible way.

"A lecturer should be able to teach in a way we can easily understand and remember."

\section{Happiness}

Most students claimed that a lecturer should have a pleasant, friendly appearance.

"We always appreciate a lecturer who has a pleasant smile."

"We expect sense of humour from the lecturers."

\section{Honesty}

Students mentioned that a lecturer should teach objectively and fairly.

"A lecturer should talk honestly. He should not cheat the students."

\section{Loyalty}

Students want their lecturers to be loyal to their medical school and to their country. Criticizing their medical school and comparing it with others was considered unpropitious.

"A lecturer should love the country and the medical school and should never criticize them."

"A lecturer should possess good attitudes towards the medical students and the medical school."

"A lecturer should give priority to work in the faculty with the intention of improving it."

\section{Personal appearance}

Students preferred professionally dressed lecturers.

"It is easier to concentrate on the lecture, when the lecturer is dressed nicely and neatly."

\section{Qualified}

Students wanted lecturers with relevant higher educational qualifications.

"A lecturer should be qualified to prepare exams and assess students. Sometimes we are being taught by one person and assessed by another. This is an impediment to obtaining good results."

\section{Lecture preparation procedure}

Content development (develops a clear and concise message)

Many students mentioned that they expect lecturers to teach according to the designated curriculum, with a focus on the most relevant material.

"I expect to have a lecturer who carefully selects and decides the amount of facts that is going to be presented. We should not be overdosed."

"It is better if the lecturer can make us note down the important points."

Students demanded exam-oriented teaching that connects the basic sciences to their clinical work. They further desired to have a lecturer who prepares for the lesson, cognizant of the existing knowledge of students.

"He should be able to realize that some students do not know anything and sits in the lecture hall waiting to collect knowledge."

Some students also stated that a lecturer should provide them with relevant information about ongoing advances in medicine.

"I think, in order to face the ongoing competition within the field of medicine, a lecturer should equip us with up-to-date knowledge."

Content organization (applies concepts using real world situations to simplify content)

Students mentioned that they enjoy when lecturers relate their past clinical experiences to lecture content, as it provides them with concrete examples.

"When the lecturer integrates his experiences when presenting facts, the lecture will not be forgotten easily."

Students welcomed a lecturer who teaches according to a clear and organized syllabus.

"The points in a lecture should be organized and interconnected."

Many students stated that providing a summary at the end of the lesson is worthwhile, and that it would be helpful if they could have a set of notes before the lecture began. 
Content design (create support visuals that enhance teaching)

Students commented about utilization of visual aids. While preparing slides in a clear and creative manner was appreciated, it is not an excuse to simply read from the PowerPoint.

"The slides of a PowerPoint presentation should not contain large paragraphs. When diagrams, flow charts, pictures or videos are used, they embedded in our mind easily and improve our understanding. It is easy to remember such presentations."

\section{Lecture delivery procedure}

\section{Speaking style}

Students confessed difficulty in understanding English, which was further propagated by convoluted medical terms. Some suggested that it would be easier to understand if the lecturer explains the difficult words in their native language.

"Most of us cannot understand English. Though the lecturer has more knowledge in language and grammar, lecture is not a place to exhibit their fluency in language."

Students further commented on the pace of the lecture.

"Lecture should be at a speed that allows understanding the subject and taking down notes."

"There should be a gap between each sentence. It is better to repeat important statements."
Students were concerned about the duration.

"We wish our lecturers would not continue for more than forty-five to sixty minutes at a stretch."

"We hate the last half an hour when the lecture is too long."

They suggested giving breaks when they are bored, or regaining their attention by humour.

\section{Additional sense stimulation}

Students welcome lecturers who use multiple visual aids such as PowerPoint, the overhead projector, and the white board at the same time.

\section{Interaction}

Students expected the lecturer to be physically active and interact with students during the lecture.

"It is good to have a lecturer who walks through the class room and converse with students."

There were several responses about questions being asked from them during the lecture. They disliked lecturers who ask too many questions. Pointing out and embarrassing students was considered stressful.

"When the lecture keeps on asking questions from us in front of others it makes us tense and amnesic."

"They should teach first and then ask questions."

Table 1: Response categories and key words of students' perceptions of a university lecturer

\begin{tabular}{|c|c|}
\hline Themes sub-theme and their definition & Responses \\
\hline \multicolumn{2}{|r|}{ Personal qualities } \\
\hline $\begin{array}{l}\text { Expertise (Jahangiri \& Mucciolo, 2008, } \\
\text { Onwuegbuzie et al., 1997, Kane et al., 2004) } \\
\text { Logically explains or simplifies the materials }\end{array}$ & $\begin{array}{l}\text { Knowledgeable, skilled, talented, attention, train, guide, improve, } \\
\text { quality- }\end{array}$ \\
\hline $\begin{array}{l}\text { Empathy (Jahangiri \& Mucciolo, 2008, } \\
\text { Onwuegbuzie et al., 1997, Kane et al., 2004) }\end{array}$ & \multirow{2}{*}{$\begin{array}{l}\text { Empathy, Accept mistakes, able to think like students, } \\
\text { understanding feelings of students, understand social handicaps, } \\
\text { understand knowledge level, understand work loads of students, } \\
\text { understand needs, understand types of students, humane, flexible }\end{array}$} \\
\hline $\begin{array}{l}\text { Sees and understands the perspective of the } \\
\text { student }\end{array}$ & \\
\hline $\begin{array}{l}\text { Approachable (Jahangiri \& Mucciolo, } 2008, \\
\text { Kane et al., 2004, Onwuegbuzie et al., 1997, } \\
\text { Rosip \& Hall, 2004) } \\
\text { Appears friendly and receptive to comments } \\
\text { and interact }\end{array}$ & $\begin{array}{l}\text { Friendly, kind, approachable, close, speak individually, patient, } \\
\text { free to talk, listen to student good approach }\end{array}$ \\
\hline
\end{tabular}


Happiness (Jahangiri \& Mucciolo, 2008,

Kane et al., 2004, Rosip \& Hall, 2004)

Evidently enjoys giving the presentation
Humour, pleasant smile, nice to see
Energy (Jahangiri \& Mucciolo, 2008,

Onwuegbuzie et al., 1997)

Demonstrate liveliness in sharing knowledge
Active, liveliness

Inspiration (Jahangiri \& Mucciolo, 2008,

Onwuegbuzie et al., 1997)

Student feels encouraged to incorporate learned concept

\section{Dedicated}

Working hard and with effort considering teaching is important*

\section{Qualified}

Have achieved the standard of ability or knowledge needed*
Make us curious, impress, interesting, relevant

Dedicated, devoted, maximum use of time, responsible

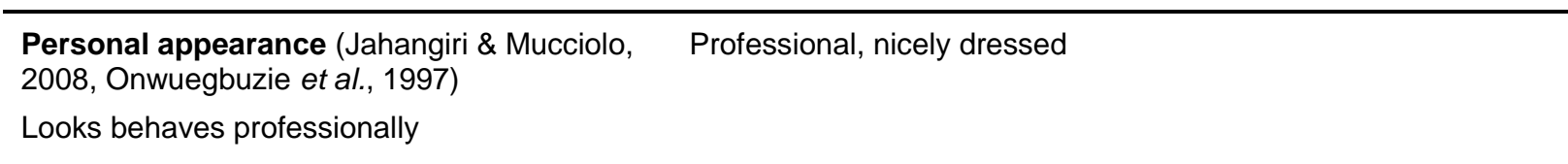

Self confidence (Jahangiri \& Mucciolo, 2008, Onwuegbuzie et al., 1997)

Self confidence, prepared, good performance,

Adequately qualified, Relevantly qualified, experienced, post graduate qualifications, subject oriented qualifications

Appears prepared and in control of the presentation of discussion, regardless of the audience size, level of expertise or rank

Honest
To say exactly what they mean* Honest

Caring (Jahangiri \& Mucciolo, 2008,
Onwuegbuzie et al., 1997, Kane, 2004)
Viewed by the student as genuine and
sincere

\begin{tabular}{ll}
\hline Loyal & Loyal to the faculty \\
Remaining faithful to the school and country* & Loyal to the country
\end{tabular}

\section{Lecture preparation}

Content development -develops a clear and concise message (Jahangiri \& Mucciolo, 2008, Onwuegbuzie et al., 1997)
Clearly explains, exist in mind, explain in simple manner, clear, understandable, easily registered, well explain, systematic, simplify difficult word, easy to fit in , easy short methods ,tells stories
Content organization (Kane, 2004) Applies concepts using real world situations to simplify content (Jahangiri \& Mucciolo, 2008)

Content design (Jahangiri \& Mucciolo, 2008)

Creates support visuals that enhance the teaching without distracting from the lecture
Include all facts, include concepts, relevant to curriculum, summarize, well planned, provide references, revise ,orderly manner, interrelated, exam oriented, clinically oriented, related to practical, according to objectives, starts from basic

Diagrams, pictures, flow charts, videos, animation, diversity, attractiveness, short massage, clear hand writing,

(Negative- Long paragraphs, more sentences) 


\section{Lecture delivery}

Speaking style (Onwuegbuzie et al., 1997, Rosip \& Hall, 2004) Can be easily understood while using proper inflection and tone when speaking

Clear language, simple language correct language, easily understandable language, simple English, clear voice, active voice, loud voice, attractive use of language, clarify in mother tongue, fluent, proper speed, pause between sentences, take time, slowly, normal pace, time to take notes, clear pronunciations

(Negative- complex words, difficult words, rushing through slides)

Additional sense stimulation (Jahangiri \& Mucciolo, 2008, Rosip \& Hall, 2004)

Appeals to multiple senses at the same time
Simultaneous use of several media, providing lecture note before the lecture, make student write during lecture

(Negative-Just reading power point)
Interaction (Jahangiri \& Mucciolo, 2008, Onwuegbuzie et al., 1997)

Establishes an interaction with the students/audience through questions, comments, and other participations
Communicate well, interactive discussions during lecturers, discussion outside lecturer topic, questioning, explaining, conversation, keep student awake

(Negative- too many questions pointing to student embarrass, questioning, stress)
Body language style (Jahangiri \& Mucciolo, 2008, Onwuegbuzie et al., 1997, Rosip \& Hall, 2004)

Uses physical movements and gesturers to support the presentation
Relaxed, standing, close to audience, walking through class room

(Negative- sitting while lecturing)

\section{Discussion}

When compared to previous studies, such as those of Henzi et al. (2005) and Jahangiri \& Mucciolo (2008), the needs and desires of our students are similar to previous research. Our results parallel that of Henzi et al. (2005) regarding issues of faculty supportiveness, and when compared to Jahangiri's study (2008), the request for highly trained lecturers and concerns about speaking style are analogous. While many of our findings do parallel those of previous studies, some are unique to universities in a low-resource setting, and may provide explanations to the problems that other newly established, publicly funded medical schools in developing countries may face at the embryonic stage.

Under the theme of "personal qualities," we identified two new sub themes, "honesty" and "loyalty to faculty and country," which have not been recognized in similar studies. One possible causative factor for these responses is that data collection was conducted at a time when there were doubts about the quality of education at FMAS, RUSL among peers in other medical schools and the wider medical community due to the lack of physical and human resources. The public sphere was being inundated with doubts about the quality of education being brought to their attention by visiting lecturers and clinicians, and the Sri Lanka Medical Council, the regulatory body behind medical faculty licensing, was not forthcoming. Furthermore, there was a new private medical school being established with government encouragement (Siribaddana et al, 2012) and students were worried about allocation of resources. These findings reveal a new aspect about obtaining medical education in a limited-resource setting: fear. While students are working to obtain the best medical education they can, there are unyielding surrounding concerns about whether they will be allowed to continue this education at their university. Thus, this new quality of being loyal to one's medical school has arisen. Students studying in a lowresource setting need their lecturers to believe in them and the education they are receiving, and to provide a united front in the fight to obtain additional funding.

Although other sub-themes appear to be similar to what is reported, observation of their verbatim expressions reveals that some are dealt with more attention and detail. 
For example, "understanding the student problems and needs" which is a commonly found in literature (Schönwetter et al., 2006) is expressed repeatedly, and emphasizes the need to understand the background and the social handicaps of the students. The reason for these elaborated expressions may be the stressors that this group of students has faced as the initial batch in this resource poor setting.

Students have repeatedly highlighted some basic needs that are expected regarding content organization. (Table1) These include the necessity of the contents to be clinically, practically and exam oriented as well as being included within the curriculum. At this time, many of the lecturers were new and had little or no experience with medical teaching, curriculum development, or writing exams. This may be the reason for higher numbers of responses obtained for this sub-theme. These findings reveal a necessity for a mix of lecturers from different experience levels, regardless of the fact that the school is newly established. However, if this is not feasible, these results can be effectively used in devising new teacher training procedures, which will benefit future generations at FMAS, RUSL and other medical schools in limitedresource settings.

While the issue of "speaking style" is not a new find, it is an exceptionally important quality of a lecturer, especially in a country such as Sri Lanka. Up until medical school entrance, students are taught in either Sinhalese or Tamil. When the language medium suddenly changes in medical school, inability to understand and communicate in English becomes a barrier to learning. While all schools offer an initial intensive English course, it hardly fulfils the students' needs. As such, among the expectations pertaining to delivery of a lecture, "speaking style" had the highest number of responses. Students expect lecturers to use simple language and teach at a slower pace so that they can register and retain the information as well as take notes. Findings in this study reflect the importance of clear verbal delivery and open up an area for studies to identify the ways and means of minimizing this language barrier for the benefit of the students.

While visual aids can help with verbal communication difficulties, it is important that they are used in the appropriate manner. Students have emphasized issues with poorly prepared slides and lecturers merely reading the slides without any elaboration on the subject matter. Students desired lecturers who have the ability to use a combination of teaching and learning media during their lectures. This is a universal expectation and encourages the lecturers to consider developing such skills at the beginning of their careers (Dhaliwal, 2007).

While not an idea specifically developed through this study, one important aspect of teaching in a limited resource setting is the need for an enhanced relationship between students and their lecturers. The student protest movement of Sri Lanka was dominated by Marxist oriented political parties and the agitation against lack of facilities in FMAS, RUSL was in danger of being hijacked by the politically inclined-Inter University Students Front (IUSF) by combining this issue with the agitations among other university students against a private medical school. However, students were aware of the disastrous consequences of such an agitation, and worked together with lecturers to effectively lobby for the desired facilities while remaining aloof from the politically inclined IUSF.

This example reveals just a glimpse of the tensions that can arise at a limited resource university, and the need for the student-faculty relationship to be one focused on partnership rather than status. This finding challenges the statement "traditional educational relationship between a student and the teacher being converted to a pure transactional relationship between the customer and his/her supplier" (Ho \& Tani, 2007), and reveals a need for the student-faculty relationship in such settings to step outside of the traditional sphere.

When interpreting qualitative data, it is important to discuss rigor as well as error and bias. Our inability to conduct focus groups or interviews in order to achieve triangulation could have limited to our scope of understanding of the results. Similarly, by distributing an open-ended question under the cover of anonymity, it became impossible to ask any follow-up questions or receive clarification of the data. Furthermore, transferability of the results could have improved if we used a random instead of a purposive sample. We also acknowledge that by distributing the question in multiple languages but reporting it in English, some information or meaning could have been lost in translation. 


\section{Conclusions}

In conclusion, although attributes of lecturers expected by the students are namely similar to what is reported elsewhere, this study has brought clarity to the most important lecturer qualities for students in a low resource setting. In conjunction with the emotional stressors, special focus should be given to overcoming language barriers when creating teachertraining manuals. Furthermore, this unique find of a desire for loyalty is one that could be further examined, as well as the interesting outside tensions that can affect the studentfaculty relationship. Despite the increasing emphasis on student autonomy, this study confirms the important responsibilities of lecturers in providing quality medical education, and brings to light additional challenges of doing so in a resource poor environment.

\section{Acknowledgement}

Brandon Sia

\section{References}

Berg, B.L. (2001) Qualitative Research Methods for the Social Sciences, Boston: Pearson.

Boyatzis, R. (1998) Transforming qualitative information: Thematic analysis and code development, Thousand Oaks CA: Sage.

Dhaliwal, U. (2007) A prospective study of medical students' perspective of teaching-learning media: reiterating the importance of feedback, Journal of the Indian Medical Association, 105, 11 , pp. 621-623.

Glaser, B.G., Strauss, A.L. (1967) The Discovery of Grounded Theory, Strategies for Qualitative Research, New York: Aldine.

Henzi D., Davis, E., Jasinevicius, R., Hendricson, W., Cintron, L. \& Isaacs, M., (2005) Appraisal of the dental school learning environment: the students' view, Journal of Dental Education, 69, 10, pp. 1137-1147.

Ho, M.T. \& Tani, M., (2007) What medical students value from their teachers, Australian Health Revolution, 31, 3, pp.358-361.

Horsfall, D., Byrne-Armstrong, H.\& Higgs, J., (2001). Critical moments in qualitative research. In Researching critical moments, 2001, 3, p.16.

Jahangiri, L. \& Mucciolo, T.W., (2008) Characteristics of effective classroom teachers as identified by students and professionals: a qualitative study, Journal of Dental Education, 72, 4, pp. 484-493.

Kane, R., Sandretto, S. \& Health, C. (2004) An investigation into excellent tertiary teaching: Emphasizing reflective practice, Higher Education, 47, 3, pp. 283-310.

Khan, I. \& Fareed, A. (2003) Perceptions of students and faculty about conventional learning and community-oriented medical education, Journal of the College of Physicians and Surgeons Pakistan, 13, 2, pp. 82-85.

Maheux, B., Beaudoin, C., Berkson, L., Côté, L., Marchais, J.D. \& Jean, P. (2000) Medical faculty as humanistic physicians and teachers: the perceptions of students at innovative and traditional medical schools, Medical Education, 34,8 , pp. 630-634.

Nahar, N., Talukder, H.K., Khan, T.H., Mohammad, S. \& Nargis, T. (2010) Students' Perception of Educational Environment of Medical Colleges in Bangladesh, Bangabandhu Sheikh Mujib Medical University Journal, 3, 2.

Onwuegbuzie, A.J., Witcher, A.E., Collins, K.M.T., Filer, J.D., Weidmaier, C.D. \& Moor, C.W. (1997) Students' perceptions of characteristics of effective college teachers a validity study of a teaching evaluation form using a mixed methods analysis, American Educational Research Journal, 44, 1, pp. 113.

Pai, A. (1993) How to help your child succeed, New Delhi: USB Publishers Distributers.

Redding, S. \& Walberg H.J. (2012) Promoting Learning in Rural Schools Lincoln, Illinois: Center on Innovation \& Improvement.

Rosip, J.C. \& Hall, J.A. (2004) Knowledge of nonverbal cues, gender and nonverbal decoding accuracy, Journal of Nonverbal Behavior, 28, 4, pp. 267-286.

Schönwetter, D.J., Lavigne, S., Mazurat, R.\& Nazarko, O. (2006) Students' Perceptions of Effective Classroom and Clinical Teaching in Dental and Dental Hygiene Education, Journal of Dental Education, 70, p. 6.

Siribaddana, N., Agampodi, S. \& Siribaddana, S., (2012) Private medical education in Sri Lanka Indian Journal of Medical Ethics, 9, 4, pp. 269271.

Zhang, Y.\& Wildemuth, B.M., (2009) Qualitative analysis of content, Applications of Social Research Methods to Questions in Information and Library Science, pp. 308-319. 